\title{
Dual-labeling with 5-aminolevulinic acid and fluorescein for fluorescence-guided resection of high-grade gliomas: technical note
}

\author{
Eric Suero Molina, MD, MBA, ${ }^{1}$ Johannes Wölfer, MD, ${ }^{1}$ Christian Ewelt, MD, ${ }^{1}$ André Ehrhardt, PhD, ${ }^{2}$ \\ Benjamin Brokinkel, MD, ${ }^{1}$ and Walter Stummer, MD' \\ 1'Department of Neurosurgery, University Hospital Münster; and ${ }^{2}$ Karl Storz GmbH \& Co., Tuttlingen, Germany
}

\begin{abstract}
OBJECTIVE Fluorescence guidance with 5-aminolevulinic acid (5-ALA) helps improve resections of malignant gliomas. However, one limitation is the low intensity of blue light for background illumination. Fluorescein has recently been reintroduced into neurosurgery, and novel microscope systems are available for visualizing this fluorochrome, which highlights all perfused tissues but has limited selectivity for tumor detection. Here, the authors investigate a combination of both fluorochromes: 5-ALA for distinguishing tumor and fluorescein for providing tissue fluorescence of adjacent brain tissue.
\end{abstract}

METHODS The authors evaluated 6 patients who harbored cerebral lesions suggestive of high-grade glioma. Patients received 5-ALA (20 mg/kg) orally 4 hours before induction of anesthesia. Low-dose fluorescein ( $3 \mathrm{mg} / \mathrm{kg}$ intravenous) was injected immediately after anesthesia induction. Pentero microscopes (equipped either with Yellow 560 or Blue 400 filters) were used to visualize fluorescence. To simultaneously visualize both fluorochromes, the Yellow 560 module was combined with external blue light illumination (D-light C System).

RESULTS Fluorescein-induced fluorescence created a useful background for protoporphyrin IX (PPIX) fluorescence, which appeared orange to red, surrounded by greenly fluorescent normal brain and edematous tissue. Green braintissue fluorescence was helpful in augmenting background. Levels of blue illumination that were too strong obscured PPIX fluorescence. Unspecific extravasation of fluorescein was noted at resection margins, which did not interfere with PPIX fluorescence detection.

CONCLUSIONS Dual labeling with both PPIX and fluorescein fluorescence is feasible and gives superior background information during fluorescence-guided resections. The authors believe that this technique carries potential as a next step in fluorescence-guided resections if it is completely integrated into the surgical microscope.

https://thejns.org/doi/abs/10.3171/2016.11.JNS161072

KEY WORDS PPIX; fluorescein; malignant glioma; ALA; fluorescence-guided resection; oncology

$\mathrm{M}$ AXIMAL safe resection of malignant gliomas as the first step of multimodal therapy is an accepted goal in malignant glioma surgery. ${ }^{18,23,26,31,38}$ This aim is not always easily achieved, since the borders of the contrast-enhancing part of the tumor are often difficult to distinguish using conventional white-light microscopy. For this reason, several tools have been introduced, such as intraoperative imaging by ultrasound, MRI, or CT. $5,6,19,45,46$ The use of 5-aminolevulinic acid (5-ALA) is another well-established method first introduced to neurosurgery in $1998.40,42$ Since then, extensive basic and clinical research, including a Phase 3 randomized trial, have been performed. ${ }^{10,12,17,39,43,44}$ As a nonfluorescent biochemical precursor of hemoglobin, 5-ALA leads to intracellular synthesis and accumulation of fluorescent protoporphyrin IX (PPIX) in malignant neoplasms..$^{15,30,40,42}$ Commercially available microscopes equipped with blue-violet excitation light are used for visualizing PPIX fluorescence. Such microscopes are available from all major microscope manufacturers. Red fluorescence highlighting viable tumor cells is visualized on a dark blue-green background. The bluegreen background is essential for obtaining tissue detail to enable resections under the light conditions needed for fluorescence visualization and is based on emission filter

ABBREVIATIONS 5-ALA = 5-aminolevulinic acid; PPIX = protoporphyrin IX.

SUBMITTED April 25, 2016. ACCEPTED November 11, 2016.

INCLUDE WHEN CITING Published online March 24, 2017; DOI: 10.3171/2016.11.JNS161072. 
characteristics. These filters allow transmission of autofluorescence, and a small part of the remitted excitation light (375-440 $\left.\mathrm{nm}^{40}\right)$. Under normal circumstances, this combination of autofluorescence and remitted light is usually regarded as giving sufficient background information. Under certain circumstances, background illumination may be considered too weak, requiring a frequent change of the filters to white light for visualizing anatomy, for reorientation, or for hemostasis.

Based in part on the acceptance of fluorescence-guided resection using 5-ALA, a second fluorochrome, fluorescein, which is approved for retinal angiography, has recently gained attention in the context of glioma surgery. First described in 1948 by G. E. Moore for finding and resecting intrinsic brain tumors in the age of air ventriculography, ${ }^{25}$ Moore discussed possible merits for detecting tumor but already noted fluorescence in edematous brain. After the initial description, and ultimately in the late 20th century, a number of articles discussing the use of fluorescein were published. ${ }^{16,20,21}$ Fluorescein sodium provides strong fluorescence and, apart from infrequent anaphylactic reactions and seizures, appears to be safe, especially when the applied doses are low. ${ }^{9,13,22}$ With the introduction of the recent generation of surgical microscopes with new filters, e.g., the Yellow 560 system (Carl Zeiss) or the FL560 System (Leica Microsystems), fluorescein sodium is experiencing renewed attention in the field of fluorescence imaging. ${ }^{1,27,28,32,33}$ In past publications, several advantages of fluorescein over 5-ALA have been pointed out. However, controversy has ensued because of the fact that after intravenous administration of fluorescein, fluorescence can be found in all perfused tissue-being in plasma-and is consequently extravasated whenever the blood-brain barrier is breached, e.g., at resection margins. ${ }^{8,34,37}$ With this study, we now explore a previously unreported (to our knowledge) different path for utilizing fluorescein fluorescence based on its presence in all perfused tissue. We aimed at combining the selective accumulation of 5-ALA-induced porphyrins for reliable tumor detection, and fluorescein for providing background information by simultaneously visualizing both fluorochromes. This combination would entail a number of evident advantages, provided that the approach is feasible, overcoming some of the limitations of fluorescence-guided resections with fluorescein using blue light incorporated into commercially available, conventional microscopes alone. Yellow-green fluorescein emission light would not interfere with red tumor fluorescence as is the case when trying to illuminate background tissue with additional external light sources. Better background visualization would obviate the requirement of frequently changing between fluorescence and white light modes of the surgical microscope and would be expected to accelerate surgery while maintaining safety and efficacy. Less frequent changes between illumination modalities would reduce the necessity for habituating between high and low illumination conditions by the surgeon, increasing comfort and possibly safety. Bleaching of 5-ALA-induced porphyrins from white light would be reduced, if phases of white light surgery were shortened.

\section{Methods}

We evaluated 6 patients undergoing microscopic fluorescence-guided resection for cerebral lesions suggestive of high-grade glioma, aiming for better intraoperative visualization of tumor and adjacent tissue (Table 1). By using fluorescein, we hoped for more rapid surgery due to the better visualization of tumor tissue, while operating on a brighter background, as previously reported. ${ }^{1,2}$

Written informed consent was obtained from all patients included in this series after consultation with the ethics committee regarding compassionate use of a drug in an off-label setting, aiming at improving resection and comparing fluorescein with the gold standard for fluorescence-guided resection, 5-ALA. Approval was granted by the ethics committee for a retrospective compilation of data from this cohort. Prior to surgery, each case was discussed by the tumor board and, in accordance with the interdisciplinary decision, surgery was proposed. Patients received 5-ALA (Gliolan, Medac) at a dose of $20 \mathrm{mg} / \mathrm{kg}$ body weight 4 hours before induction of anesthesia; lowdose fluorescein $(3 \mathrm{mg} / \mathrm{kg}$ intravenous; Fluorescein Alcon $10 \%$, Alcon Pharma $\mathrm{GmbH}$ ) was injected immediately after anesthesia induction, as previously described. ${ }^{1}$ Zeiss Pentero (Carl Zeiss) microscopes equipped with either a Blue 400 or Yellow 560 filter were used during resection.

\section{Filter Combinations for Dual Visualization}

The excitation maximum of fluorescein, i.e., the wavelength at which the strongest fluorescence is generated, is at $480 \mathrm{~nm} .{ }^{35}$ In comparison, the excitation maximum of 5-ALA-derived porphyrins is $405 \mathrm{~nm}$, which represents the Soret band of PPIX ${ }^{42}$ (Fig. 1). The fluorescence maximum for fluorescein is $525 \mathrm{~nm},{ }^{22}$ whereas maximal fluorescence of PPIX is found at $635 \mathrm{~nm}$ with a smaller, secondary peak at $704 \mathrm{~nm} \cdot{ }^{27}$ Thus, using excitation light as

TABLE 1. Details in 6 patients who underwent microscopic fluorescence-guided resection for cerebral lesions suggestive of high-grade glioma

\begin{tabular}{ccllllll}
\hline Case No. & Sex & Histology & Location & Side & MGMT & IDH-1 & GTR \\
\hline 1 & F & Metastasis & Frontal & Lt & - & - & Yes \\
\hline 2 & F & GBM & Temporal & Lt & Methylated & Negative & Yes \\
\hline 3 & F & GBM & Parietal & Rt & Unmethylated & Negative & Yes \\
\hline 4 & F & GBM & Frontal & Lt & Unmethylated & Negative & Yes \\
\hline 5 & F & GBM & Occipital & Lt & Unmethylated & Negative & Yes \\
\hline 6 & F & GBM & Frontal & Rt & Methylated & Negative & Yes \\
\hline
\end{tabular}

GBM = glioblastoma; GTR = gross-total resection; - = not performed . 


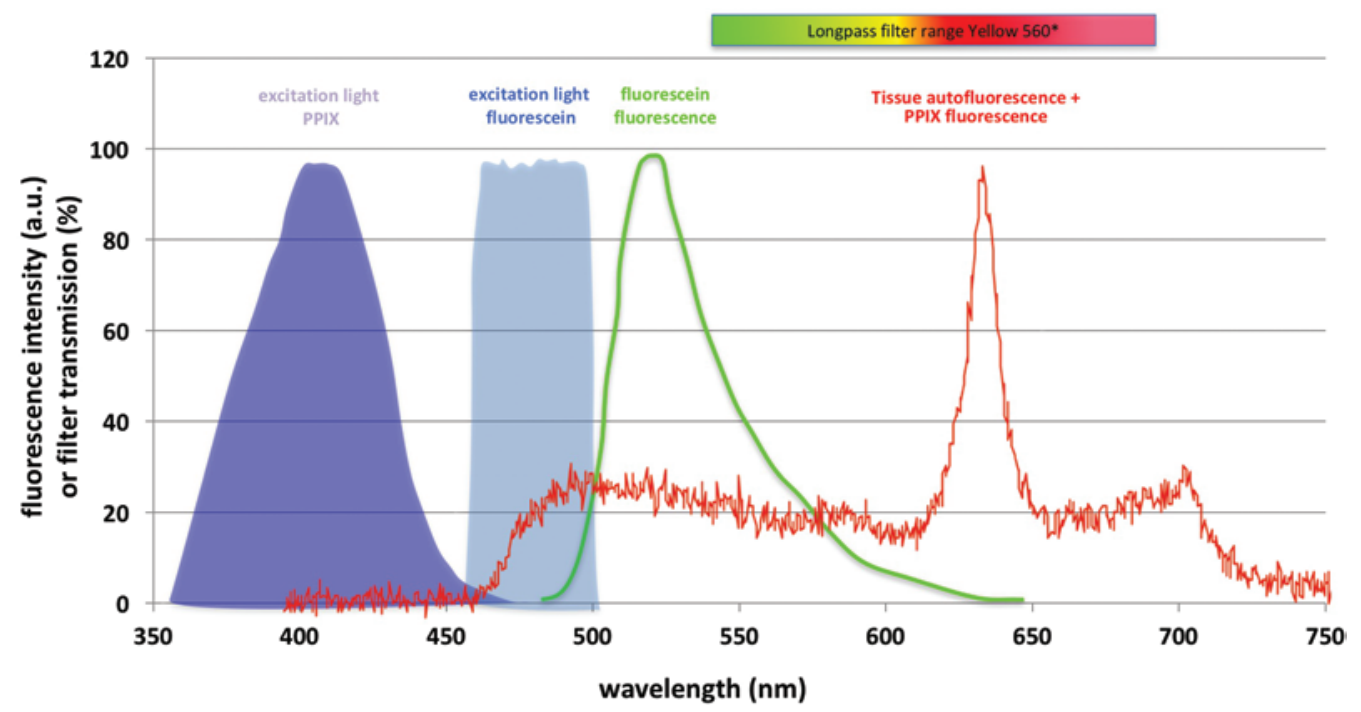

FIG. 1. Scheme according to manufacturer's specifications and literature review of fluorescein and protoporphyrin fluorescence demonstrating the possibility of visualizing both fluorescences with the Yellow 560 module from the Zeiss Pentero 900. *According to manufacturer's specifications. a.u. = arbitrary units. Figure is available in color online only.

provided by the Zeiss Yellow 560 system $(460-500 \mathrm{~nm})$ in combination with specific light for exciting protoporphyrin fluorescence (375-440 nm; D-light C System, Storz, CE approved for patient use) will specifically and optimally elicit the fluorescence of the respective fluorochrome, which can be visualized using the Yellow 560 module alone. As illustrated in Fig. 1, the 530-nm longpass filter optimized for detecting fluorescein fluorescence will also allow visualization of tissue autofluorescence, excited by blue light and PPIX fluorescence. For visualizing fluorescence, the microscope with the activated Yellow 560 filter system was positioned approximately $25 \mathrm{~cm}$ away from the surgical field and the light intensity set to $50 \%$, whereas a glass fiber light guide was used to convey violet-blue excitation light (D-light C System) to the surgical field (distance $\sim 5 \mathrm{~cm}, 100 \%$ light intensity). Ensuing images were captured using the Zeiss Pentero HD1 Video Camera (Carl Zeiss).

No surgical decisions were made based on these images. Separate biopsy samples $(n=2)$ were obtained in 2 patients from tissue solely harboring fluorescein and not 5-ALA-derived fluorescence. All samples were stained with $\mathrm{H} \& \mathrm{E}$ and elastica van Gieson. Immunohistochemical and molecular genetic analysis of glial fibrillary acidic protein (GFAP), IDH-1 mutation, Ki-67 MIB1 proliferation index, and MGMT methylation were also performed. Early postoperative MRI was performed in all patients within 48 hours after resection. Residual tumor volumes were determined by segmentation of individual slices on T1-weighted axial images without and with Gd. Gross-total resection was defined as a residual volume of enhancing tumor $<5 \%$ of the initial volume. ${ }^{23}$

\section{Results}

Administering fluorescein created a useful background for PPIX fluorescence, which appears as orange to red, surrounded by intense green fluorescence in normal brain and edematous tissue (Fig. 2). Orange fluorescence resulted from the combination of green fluorescein and red PPIX fluorescence within tumor tissue.

Using the Yellow 560 filter and only illuminating with violet-blue light (375-440 nm) allowed visualization of only isolated red PPIX fluorescence (Fig. 2B). With incremental increases of blue excitation $(460-500 \mathrm{~nm})$, the yellow fluorescence of fluorescein in tissue and tumor became visible (Fig. 2C). Co-emitted red and yellow fluorescence gave tumor tissue an orange hue. With further increases of yellow light, PPIX fluorescence was gradually concealed (Fig. 2D). The extent of visible red PPIX fluorescence as depicted using the Yellow 560 filter system was verified by comparing the image with the image obtained by the Carl Zeiss Blue 400 system (Fig. 2E; refer to Video 1 for the entire sequence).

VIDEO 1. Clip showing the dual labeling technique. Copyright

Department of Neurosurgery, University Hospital of Münster.

Published with permission. Click here to view.

At an intermediate intensity of blue light (460-500 nm) in conjunction with maximal blue-violet light (375-440 $\mathrm{nm}$ ), green brain-tissue fluorescence appeared helpful for distinguishing background while still allowing specific visualization of the tumor.

Using both methods in conjunction, we found that fluorescein fluorescence was not always able to highlight viable tumor tissue as depicted by PPIX fluorescence. Furthermore, unspecific extravasation of fluorescein was noted at resection margins, likewise differing with PPIX fluorescence, but without actually interfering with PPIX fluorescence detection.

Tissue removed intraoperatively was stained with $\mathrm{H}$ \& $\mathrm{E}$ and elastica van Gieson. Immunohistochemical and molecular genetic analyses of GFAP, $I D H-1$ mutation, $\mathrm{Ki}-67$ MIB1 proliferation index, and MGMT methylation were also performed. In addition, we obtained samples of tissue harboring fluorescein alone and not 5-ALA-derived 

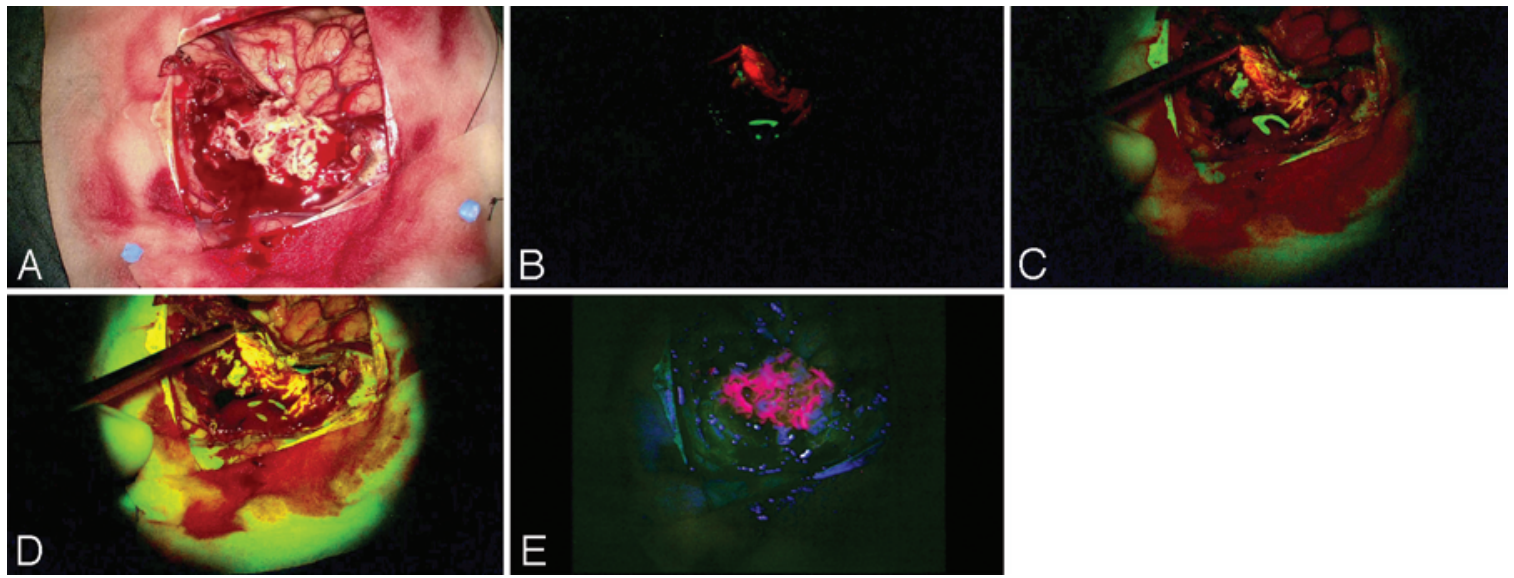

FIG. 2. Intraoperative microscopic view of a glioblastoma with conventional white light (A), Yellow 560 filter with $0 \%$ light intensity (B), Yellow 560 filter with $50 \%$ light intensity (C), Yellow 560 filter with 100\% intensity, (D), and Blue 400 filter (E). Figure is available in color online only.

fluorescence from tumor margins in our first 2 patients. However, histopathological evaluation of these tissues did not confirm the presence of tumor cells; thus, we did not remove tissue highlighted by fluorescein alone in the remaining patients. We further observed fluorescein fluorescence in the dura, cortex, and especially in edematous tissue (Fig. 2). In all cases, orange fluorescence could be observed, which implies that tumor cells harboring both PPIX embedded in a tissue matrix containing fluorescein. We did not experience any adverse effects from either fluorescein or of 5-ALA administration.

We did, however, note significant dissimilarities between the images captured by the built-in camera of the microscope and what was visible to the surgeon, with a reduced fidelity in discriminating light intensities and wavelength nuances by the camera. For illustration, we used Zeiss fluorescence phantoms for comparing images captured by the intrinsic camera to images simultaneously captured by a 12-megapixel high-definition camera through the microscope lens (Fig. 3). These images intend to illustrate limitations of the video material generated by the microscope camera, as presented in this study, in contrast to cameras with higher resolution or the surgeon's optical impression obtained using the microscope lens system.

\section{Discussion}

\section{Differential Mechanisms of Fluorescence Accumulation}

5-ALA is a prodrug that elicits the accumulation of endogenous porphyrins in malignant glioma tissue and is used as an intraoperative contrast agent. ${ }^{40}$ Technically, surgical microscopes adapted for visualizing fluorescence are constructed not only for visualizing PPIX fluorescence per se, e.g., using a longpass filter for detecting specific 635- and 704-nm emission peaks. Rather, part of the remitted blue excitation is included in the emission light pathway. This light allows discrimination of nonfluorescing tissues and is essential for surgery using the fluorescence mode of the microscope. ${ }^{42}$ However, under certain circumstances this remitted light is considered too weak, and surgeons need to shuttle between violet-blue and white light frequently during surgery. This prolongs surgery and requires the surgeon to habituate between illumination conditions, which limits the comfort and ergonomics of this approach. Furthermore, prolonged illumination with strong white light might lead to bleaching of porphyrins. ${ }^{41}$

While PPIX accumulates intracellularly and remains restricted to tumor cells ${ }^{11}$ with high selectivity, fluorescein is injected intravenously and circulates with plasma. Fluorescein has a half-life of 23.5 minutes, being converted into fluorescein monoglucoronide, which in turn has a half-life in plasma of 264 minutes. The monoglucoronide has approximately one-third the fluorescence of fluorescein. ${ }^{24}$ After intravenous administration, all perfused tissues will show fluorescence for prolonged periods of time, which will slowly subside. In regions of tissue injury or areas of blood-brain barrier breakdown, as in the angiogenic
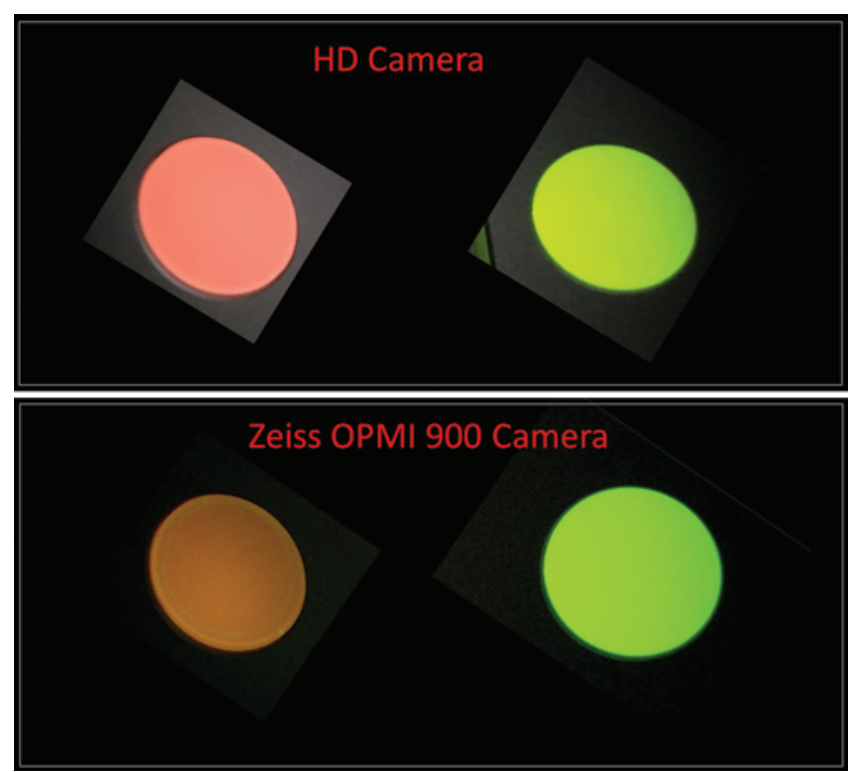

FIG. 3. Simultaneous view of fluorescence phantoms using the Yellow 560 filter in combination with specific light for exciting fluorescein (370-510 nm, D-light C System). Images captured with the microscope's own camera (upper) and a 12-megapixel HD camera through the microscope lens (lower), mimicking the surgeon's view. Figure is available in color online only. 
and enhancing regions of malignant gliomas, fluorescein will be extravasated with edema, initially highlighting the general region of blood-brain barrier perturbation without having any specific affinity to tumor cells. ${ }^{7}$ Administering fluorescein too soon before surgery leads to high concentrations in vessels and significant leakage from injured tissue with edema and blood. ${ }^{34}$

However, edema spreads into tissue and propagates through peritumoral tissue at a speed exceeding $2 \mathrm{~mm}$ per hour in humans ${ }^{14}$ and thus raises concerns about selectivity if fluorescein alone is used for trying to define marginal tumor in gliomas surgery. Furthermore, surgical injury to brain will also result in fluorescein extravasation in affected tissues. Even though this is the case in highgrade gliomas, it will further leak out during resection, since fluorescein has no specific affinity to tumor cells. ${ }^{3,36}$

\section{Varying Fluorescence During Dual Labeling}

With our present approach, we have attempted to combine the advantages of both fluorochromes, 5-ALA for selectively marking tumor, and fluorescein for-to an extent-highlighting tumor and providing background fluorescence. Differing excitation wavelengths enable selective elicitation of respective fluorescence, which could be visualized using the same long-pass filter. We found too intense blue excitation light to conceal red-orange PPIX fluorescence, indicating limitations to what might be gained. We made similar observations in all of our 6 patients.

In general, fluorescence is proportional to the amount of excitation light; thus fluorescence emission can be controlled by simply varying excitation light intensity. After oral administration of 5-ALA, tumor cells will begin accumulating PPIX fluorescence, which will peak at 6-8 hours after administration, which gradually decreases thereafter (Fig. 4). 4,29,41

Porphyrin fluorescence is visualized by using as much violet-blue $(375-440 \mathrm{~nm})$ excitation light as possible, because PPIX fluorescence is weak compared with fluorescein fluorescence. Thus, there is no reasonable possibility of varying PPIX fluorescence emission by reducing the respective excitation light intensity. Fluorescein fluorescence however, being much stronger, can be directly controlled by simply decreasing or increasing the illumination intensity of blue light (460-500 nm). Because fluorescein is not excited by violet-blue light, fluorescein fluorescence can be regulated as desired by the surgeon independent of PPIX fluorescence. Plasma fluorescein concentrations depend on the amount of fluorescein injected and, in addition, on the time after application; the ability to vary excitation will be a prerequisite and will enable adjusting background fluorescence as needed. Nevertheless, low concentrations injected at an early time point prior to surgery will be more desirable than higher concentrations injected at a short interval prior to resection, ${ }^{1}$ because of the much stronger fluorescence compared with porphyrin fluorescence.

\section{Limitations}

We are aware of the technical limitations of our setup, especially regarding the possibility of documenting the surgeon's visual impression through the microscope lens

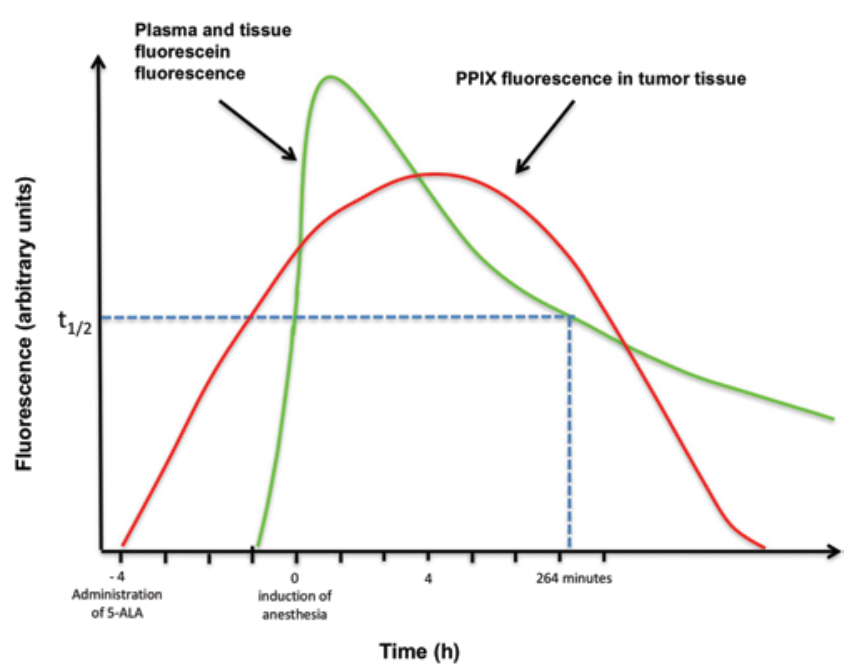

FIG. 4. Scheme illustrating the pharmacokinetics of intravenously applied fluorophores, which reach the tumor via the broken-down bloodbrain barrier. After injection, concentrations in vessels and therefore in all perfused tissues are high. Extravasation within the tumor leads to colocation of fluorophore in the tumor, resulting in a period of pseudoselectivity, which can be used for fluorescence-guided detection. Fluorophore extravasated in the tumor spreads with edema into perilesional tissue at a speed of approximately $2 \mathrm{~mm} / \mathrm{hr}$. These physiological phenomena need to be considered when using such fluorophores for fluorescenceguided resections. Figure is available in color online only.

system. Unfortunately, as depicted in Fig. 3, the resolution and dynamics of the camera systems presently used in Zeiss microscopes, although being good, do not approach the resolution or dynamic range covered by the human eye. The documentation provided in this report is limited to the available video material.

This report defines the basic technical concept and background and shows feasibility in a small cohort of patients. We cannot at this stage provide detailed proof of whether using the dual-labeling technique will in fact translate into shorter durations of surgery while maintaining safety and resection efficacy. At present, we are in the final planning stages of a small, randomized study with appropriate hardware, which will measure the duration of tumor resections and the duration of the use of the different fluorescence modes in a much larger cohort. We anticipate results from this monocentric study within 2.5 years.

For the moment, the use of fluorescein should be limited to clinical studies, because fluorescein as a compound approved for retinal angiography but not for brain tumor surgery, where it is off label. This aspect needs to be observed when using this compound.

\section{Conclusions}

Dual labeling with both PPIX and fluorescein fluorescence is feasible as deduced from our experience using both fluorochromes simultaneously. We did not find fluorescein helpful for discriminating additional tumor; rather, we found that fluorescein enhanced the depiction of background during fluorescence-guided resections. We believe that combining both fluorochromes carries potential as a next step in fluorescence-guided resections if completely integrated into the surgical microscope. 


\section{References}

1. Acerbi F, Broggi M, Broggi G, Ferroli P: What is the best timing for fluorescein injection during surgical removal of high-grade gliomas? Acta Neurochir (Wien) 157:13771378,2015

2. Acerbi F, Broggi M, Eoli M, Anghileri E, Cuppini L, Pollo B, et al: Fluorescein-guided surgery for grade IV gliomas with a dedicated filter on the surgical microscope: preliminary results in 12 cases. Acta Neurochir (Wien) 155:1277-1286, 2013

3. Berger MS: The fluorescein-guided technique. Neurosurg Focus 36(2):E6, 2014

4. Bissonnette R, Zeng H, McLean DI, Korbelik M, Lui H: Oral aminolevulinic acid induces protoporphyrin IX fluorescence in psoriatic plaques and peripheral blood cells. Photochem Photobiol 74:339-345, 2001

5. Coburger J, Merkel A, Scherer M, Schwartz F, Gessler F, Roder C, et al: Low-grade glioma surgery in intraoperative magnetic resonance imaging: results of a multicenter retrospective assessment of the German Study Group for Intraoperative Magnetic Resonance Imaging. Neurosurgery 78:775-786, 2015

6. Coburger J, Scheuerle A, Thal DR, Engelke J, Hlavac M, Wirtz CR, et al: Linear array ultrasound in low-grade glioma surgery: histology-based assessment of accuracy in comparison to conventional intraoperative ultrasound and intraoperative MRI. Acta Neurochir (Wien) 157:195-206, 2015

7. Diaz RJ, Dios RR, Hattab EM, Burrell K, Rakopoulos P, Sabha N, et al: Study of the biodistribution of fluorescein in glioma-infiltrated mouse brain and histopathological correlation of intraoperative findings in high-grade gliomas resected under fluorescein fluorescence guidance. J Neurosurg 122:1360-1369, 2015

8. Diez Valle R, Tejada Solis S: Answer to: "sodium fluorescein-guided resection under the YELLOW 560-nm surgical microscope filter in malignant brain tumor surgery-a feasibility study" (April 2013, volume 155, issue 4, pp 693-69). Acta Neurochir (Wien) 155:1319-1320, 2013 (Letter)

9. Dilek O, Ihsan A, Tulay H: Anaphylactic reaction after fluorescein sodium administration during intracranial surgery. $\mathbf{J}$ Clin Neurosci 18:430-431, 2011

10. Etminan N, Peters C, Lakbir D, Bünemann E, Börger V, Sabel MC, et al: Heat-shock protein 70-dependent dendritic cell activation by 5 -aminolevulinic acid-mediated photodynamic treatment of human glioblastoma spheroids in vitro. Br J Cancer 105:961-969, 2011

11. Ewelt C, Nemes A, Senner V, Wölfer J, Brokinkel B, Stummer W, et al: Fluorescence in neurosurgery: Its diagnostic and therapeutic use. Review of the literature. J Photochem Photobiol B 148:302-309, 2015

12. Floeth FW, Sabel M, Ewelt C, Stummer W, Felsberg J, Reifenberger $\mathrm{G}$, et al: Comparison of ${ }^{18} \mathrm{~F}-\mathrm{FET}$ PET and 5-ALA fluorescence in cerebral gliomas. Eur J Nucl Med Mol Imaging 38:731-741, 2011

13. Gombos GM, Lieberman RM: Seizures associated with fluorescein angiography. Ann Ophthalmol 21:89-90, 1989

14. Gröger U, Huber P, Reulen HJ: Formation and resolution of human peritumoral brain edema. Acta Neurochir Suppl 60:373-374, 1994

15. Idoate MA, Díez Valle R, Echeveste J, Tejada S: Pathological characterization of the glioblastoma border as shown during surgery using 5-aminolevulinic acid-induced fluorescence. Neuropathology 31:575-582, 2011

16. Kabuto M, Kubota T, Kobayashi H, Nakagawa T, Ishii H, Takeuchi H, et al: Experimental and clinical study of detection of glioma at surgery using fluorescent imaging by a surgical microscope after fluorescein administration. Neurol Res 19:9-16, 1997

17. Kamp MA, Grosser P, Felsberg J, Slotty PJ, Steiger HJ, Rei- fenberger G, et al: 5-aminolevulinic acid (5-ALA)-induced fluorescence in intracerebral metastases: a retrospective study. Acta Neurochir (Wien) 154:223-228, 2012

18. Kreth FW, Thon N, Simon M, Westphal M, Schackert G, Nikkhah G, et al: Gross total but not incomplete resection of glioblastoma prolongs survival in the era of radiochemotherapy. Ann Oncol 24:3117-3123, 2013

19. Kubben PL, ter Meulen KJ, Schijns OE, ter Laak-Poort MP, van Overbeeke JJ, van Santbrink H: Intraoperative MRIguided resection of glioblastoma multiforme: a systematic review. Lancet Oncol 12:1062-1070, 2011

20. Kuroiwa T, Kajimoto Y, Ohta T: Comparison between operative findings on malignant glioma by a fluorescein surgical microscopy and histological findings. Neurol Res 21:130134, 1999

21. Kuroiwa T, Kajimoto Y, Ohta T: Development of a fluorescein operative microscope for use during malignant glioma surgery: a technical note and preliminary report. Surg Neurol 50:41-49, 1998

22. Kwan AS, Barry C, McAllister IL, Constable I: Fluorescein angiography and adverse drug reactions revisited: the Lions Eye experience. Clin Experiment Ophthalmol 34:33-38, 2006

23. Lacroix M, Abi-Said D, Fourney DR, Gokaslan ZL, Shi W, DeMonte F, et al: A multivariate analysis of 416 patients with glioblastoma multiforme: prognosis, extent of resection, and survival. J Neurosurg 95:190-198, 2001

24. McLaren JW, Brubaker RF: Measurement of fluorescein and fluorescein monoglucuronide in the living human eye. Invest Ophthalmol Vis Sci 27:966-974, 1986

25. Moore GE, Peyton WT, French L, Walker W: The clinical use of fluorescein in neurosurgery; the localization of brain tumors. J Neurosurg 5:392-398, 1948

26. Orringer D, Lau D, Khatri S, Zamora-Berridi GJ, Zhang K, $\mathrm{Wu} \mathrm{C}$, et al: Extent of resection in patients with glioblastoma: limiting factors, perception of resectability, and effect on survival. J Neurosurg 117:851-859, 2012

27. Pogue BW, Gibbs-Strauss S: Valdés PA, Samkoe K, Roberts DW, Paulsen KD: Review of neurosurgical fluorescence imaging methodologies. IEEE J Sel Top Quantum Electron 16: $1-30,2010$

28. Rey-Dios R, Hattab EM, Cohen-Gadol AA: Use of intraoperative fluorescein sodium fluorescence to improve the accuracy of tissue diagnosis during stereotactic needle biopsy of high-grade gliomas. Acta Neurochir (Wien) 156:1071-1075, 2014

29. Rick K, Sroka R, Stepp H, Kriegmair M, Huber RM, Jacob $\mathrm{K}$, et al: Pharmacokinetics of 5-aminolevulinic acid-induced protoporphyrin IX in skin and blood. J Photochem Photobiol B 40:313-319, 1997

30. Roberts DW, Valdés PA, Harris BT, Fontaine KM, Hartov A, Fan X, et al: Coregistered fluorescence-enhanced tumor resection of malignant glioma: relationships between $\delta$ aminolevulinic acid-induced protoporphyrin IX fluorescence, magnetic resonance imaging enhancement, and neuropathological parameters. Clinical article. J Neurosurg 114:595603, 2011

31. Sanai N, Polley MY, McDermott MW, Parsa AT, Berger MS: An extent of resection threshold for newly diagnosed glioblastomas. J Neurosurg 115:3-8, 2011

32. Schebesch KM, Hoehne J, Hohenberger C, Proescholdt M, Riemenschneider MJ, Wendl C, et al: Fluorescein sodiumguided resection of cerebral metastases-experience with the first 30 patients. Acta Neurochir (Wien) 157:899-904, 2015

33. Schebesch KM, Proescholdt M, Höhne J, Hohenberger C, Hansen E, Riemenschneider MJ, et al: Sodium fluoresceinguided resection under the YELLOW $560 \mathrm{~nm}$ surgical microscope filter in malignant brain tumor surgery-a feasibility study. Acta Neurochir (Wien) 155:693-699, 2013 
34. Schwake M, Stummer W, Suero Molina EJ, Wölfer J: Simultaneous fluorescein sodium and 5-ALA in fluorescence-guided glioma surgery. Acta Neurochir (Wien) 157:877-879, 2015

35. Sjöback R, Nygren J, Kubista M: Absorption and fluorescence properties of fluorescein. Spectrochim Acta A Mol Biomol Spectrose 51:L7-L21, 1995

36. Stummer W: Factors confounding fluorescein-guided malignant glioma resections: edema bulk flow, dose, timing, and now: imaging hardware? Acta Neurochir (Wien) 158:327328, 2016

37. Stummer W: Fluorescein in brain metastasis and glioma surgery. Acta Neurochir (Wien) 157:2199-2200, 2015

38. Stummer W, Meinel T, Ewelt C, Martus P, Jakobs O, Felsberg J, et al: Prospective cohort study of radiotherapy with concomitant and adjuvant temozolomide chemotherapy for glioblastoma patients with no or minimal residual enhancing tumor load after surgery. J Neurooncol 108:89-97, 2012

39. Stummer W, Pichlmeier U, Meinel T, Wiestler OD, Zanella F, Reulen HJ: Fluorescence-guided surgery with 5-aminolevulinic acid for resection of malignant glioma: a randomised controlled multicentre phase III trial. Lancet Oncol 7:392 401, 2006

40. Stummer W, Stepp H, Möller G, Ehrhardt A, Leonhard M, Reulen HJ: Technical principles for protoporphyrin-IX-fluorescence guided microsurgical resection of malignant glioma tissue. Acta Neurochir (Wien) 140:995-1000, 1998

41. Stummer W, Stocker S, Novotny A, Heimann A, Sauer O, Kempski $O$, et al: In vitro and in vivo porphyrin accumulation by $\mathrm{C} 6$ glioma cells after exposure to 5-aminolevulinic acid. J Photochem Photobiol B 45:160-169, 1998

42. Stummer W, Stocker S, Wagner S, Stepp H, Fritsch C, Goetz $\mathrm{C}$, et al: Intraoperative detection of malignant gliomas by 5-aminolevulinic acid-induced porphyrin fluorescence. Neurosurgery 42:518-526, 1998

43. Stummer W, Tonn JC, Goetz C, Ullrich W, Stepp H, Bink A, et al: 5-Aminolevulinic acid-derived tumor fluorescence: the diagnostic accuracy of visible fluorescence qualities as corroborated by spectrometry and histology and postoperative imaging. Neurosurgery 74:310-320, 2014

44. Stummer W, Tonn JC, Mehdorn HM, Nestler U, Franz
$\mathrm{K}$, Goetz C, et al: Counterbalancing risks and gains from extended resections in malignant glioma surgery: a supplemental analysis from the randomized 5-aminolevulinic acid glioma resection study. Clinical article. J Neurosurg 114:613-623, 2011

45. Terpolilli NA, Rachinger W, Kunz M, Thon N, Flatz WH, Tonn JC, et al: Orbit-associated tumors: navigation and control of resection using intraoperative computed tomography. J Neurosurg 124:1319-1327, 2016

46. Unsgaard G, Ommedal S, Muller T, Gronningsaeter A, Nagelhus Hernes TA: Neuronavigation by intraoperative three-dimensional ultrasound: initial experience during brain tumor resection. Neurosurgery 50:804-812, 2002

\section{Disclosures}

Dr. Stummer reports that he receives speaker fees from Medac and Carl Zeiss.

\section{Author Contributions}

Conception and design: Suero Molina, Ehrhardt, Brokinkel, Stummer. Acquisition of data: Suero Molina, Wölfer, Ewelt, Stummer. Analysis and interpretation of data: Suero Molina, Wölfer, Brokinkel, Stummer. Drafting the article: Suero Molina, Stummer. Critically revising the article: Suero Molina, Wölfer, Ewelt, Brokinkel, Stummer. Reviewed submitted version of manuscript: Suero Molina, Wölfer, Ewelt, Ehrhardt, Stummer. Approved the final version of the manuscript on behalf of all authors: Suero Molina. Statistical analysis: Stummer. Administrative/technical/ material support: Suero Molina, Wölfer, Stummer. Study supervision: Suero Molina, Stummer.

\section{Supplemental Information \\ Videos \\ Video 1. https://vimeo.com/196291414.}

\section{Correspondence}

Eric Suero Molina, Department of Neurosurgery, University Hospital of Münster, Albert-Schweitzer-Campus 1, A1, Münster D-48149, Germany. email: eric.suero@ukmuenster.de. 